\title{
How to utilise students' cultural and linguistic experiences to promote language learning: Looking beyond the school
}

\author{
Dr. Tözün Issa, London Metropolitan University
}

\section{Introduction}

Britain is a multicultural and a multilingual country. There are over 300 languages spoken in London alone (The Literacy Trust, 2006) where communities thrive on inter communal systems that facilitate dynamic mechanisms for social, political, educational and economic activities (Issa, 2005). For example, on average there are 5 Turkish wedding parties a week in London alone. There is a Turkish football league consisting of two divisions (12 teams in each division) with competitions taking place every Saturday and Sunday. Each community has set up their schools that operate mostly at weekends. There are over 1500 such schools in London alone (Issa and Williams, 2009). These are vibrant, industrious communities that now have third and fourth generation children starting mainstream schools exposed mostly to the language of their home. There are issues concerning the educational attainment some of these communities. While some (Chinese, Gujerati) are doing well at school others (Somali, Turkish, Bangladeshi) are facing challenges. The factors contributing to underachievement are complex and needs to be analysed from a multidisciplinary perspective. This paper will explore the potential of utilising children culturally related experiences which is often related to their home and community activities by teachers in the mainstream ( schools run either by the government funding or supported by the Church) classroom environments. Children's linguistic skills and knowledge (in both first and second language) will be seen as central tool for the transmission of such experiences.

Community literacy is a term that is usually associated with linguistic minorities and the way the language of the community is used (and reproduced) through interactions at home as well as community based activities e.g. supplementary schools, celebration of national and religious events, and other community organised activities to cater for what they regard as 'priority needs' for themselves. Such ideas can be traced back to practices that involved the maintenance of cultural and linguistic 
heritage in a hostile and a racist country (Winder, 2004). Community literacy also relates to any communal activity that is designed to have literacy as its outcome. Here I am referring to spoken interaction by members of that community - either through own schools, community functions, celebrations or by interactions of family members at home that generates literacy work. Oral literacy is placed at the centre of all community based interactions. I am going to set the context by providing some background information on the patterns of migration to UK from all parts of the Empire.

\section{History and migration}

Britain has always been a country of newcomers. Records show the presence of minority communities dating back to the $12^{\text {th }}$ Century. There is a story behind every migration: often communities were escaping religious or political persecution or migrating for economic advancement or better educational opportunities. Settlement followed similar patterns: the formation of closely-knit communities concerned to preserve their cultural and linguistic characteristics as a defence against hostility and racism. The period following the end of the Second World War was marked by significant migration to the UK from the former Crown Colonies.

Britain has not been short of overseas settlers. Winder (2004) reports that there were French Jews in London, Lincoln, York and Norwich in the $12^{\text {th }}$ Century, before their formal expulsion en masse in 1290. In the latter part of the $18^{\text {th }}$ Century, Britain's fortunes were founded on slavery. The Morning Gazette of 1765 claimed there were as many as 30,000 'negro servants' in London alone (ibid p.129).

At the end of the Second World War nearly 9000 Ukrainian refugees arrived in Britain, displaced by the advancing Red Army as Ukraine was engulfed by the USSR (Haxell, 1979). Polish speakers have arrived in the UK in waves over the last three hundred years. Small numbers of new migrants arrived in the wake of the Solidarity Movement in the 1980s. Following Poland's entry into the European Union the UK is proving to be a popular destination. During the 1990s war-torn zones in the Balkans forced refugees from Bosnia and Kosova flee to the UK. Similarly lifting the iron curtain enabled peoples of Russia, Romania and more recently Bulgaria, with its imminent European accession to the European Union, to seek new opportunities in Britain. 


\section{New Commonwealth immigration}

It is a common assumption that emigration from the ex-British Colonies officially began in 1948 when an old Second World War German cruiser Empire Windrush brought in 492 'intending immigrants' from Kingston, Jamaica (Jones 1977:122). But the Black presence in Britain goes back before to the days of slavery. There was migration from these Colonies well before they gained their independence. The most noticeable migration after the Second World War was from the West Indies followed by migration from India and Pakistan. Jones (1977) cites 1961 census figures confirming total emigration from the New Commonwealth as 522,933. The 1962 Commonwealth Immigration Act was designed to restrict migration by pretending to allow only the workforce needed to come into Britain. Vouchers were issued to bring people into the country as the 'needed skilled force'. In 1971 the political upheavals culminating in events in Pakistan became a catalyst in the migration of semi-skilled and unskilled villagers from what had become the newly founded state of Bangladesh (Khan, 1976).

In 1979 Britain took nearly 10,000 Vietnamese refugees from the transit camps in Hong Kong and their numbers reached 16,000 by the end of 1982 (Taylor, 1988). The military rule in Turkey caused a sizeable population of Turkish professionals and Turkish speaking Kurds to seek refuge in the UK (Issa 2005). With the arrival of refugees from Iraq and Iran the Kurdish population in Britain rose to 300,000. Personal discussion with Yashar Ismailoğlu, then head of Halkevi the Kurdish Cultural Centre in East London, during a visit in 2005 confirmed this as the official number.

The reasons for migration differed. For some, Britain was nothing more than a temporary home until they earned enough money to ensure a comfortable life back home. For others there was no question of return for fear of religious or political persecution. But survival in a foreign and often hostile environment depended on the preservation of cultural, religious and linguistic values. In practice this meant passing them on to the next generation irrespective of future plans. 


\section{Language use in multicultural settings: Cultural and linguistic implications}

Since the mid 1960s educators in England, following recommendations of major Government investigations, have implemented series of educational reforms attempting to reverse the pattern of underachievement amongst minority ethnic students (Plowden Report, 1967; Bullock Report, 1975; Swann Report, 1985). The result was massive spending plans aiming to provide 'equality of educational opportunity' for those from minority ethnic communities (for example Home Office Section 11 funding for children of the Commonwealth) and some political legislation (Race Relations Act 1976; Race Relations Amendment Act, 2000). Many argued that one of the reasons why such interventions brought about superficial changes was because of their failure to "leave a deep structure of relationships between educators and culturally diverse students, largely untouched" (Cummins, 1996:136). This implied an unchanging power relationship in the classroom (Kozol, 1991) which was largely due to generations of low expectations towards the minority students (Blauner, 1969; Ogbu, 1992, Mehmet Ali, 2001). Such negative attitudes often result in a long continuum of reactions ranging from internalization of a sense of ambivalence or insecurity about their identities to rejection of and active resistance to dominant group values. At both extremes the result has frequently been alienation from schooling and mental withdrawal from academic effort (Skutnabb-Kangas, 1984; Ogbu, 1992; Cummins, 1996).

\section{Some Theoretical Considerations}

Vygotsky highlights the role of language as mediating between: "the cognitive development of the individual on one hand and that individual's cultural and historical development on the other" Vygotsky (1978: 90). He also sees this as a social process: "Internal processes of cognitive development can operate only when children are interacting with people in their environment or with peers" (Op. Cit).

What Vygotsky is saying is that language is a tool through which human beings interact and acquire knowledge through socially organised activities. Vygostsky believed that talk is not a conduit through which knowledge is passed but an integral part of how understanding is collaboratively accomplished. Bakhtin (1981) on the other hand sees language as "socially and culturally formed and 
inevitably conveys value judgements and commitments" and as "invoking particular connotations, contexts and power relationships" (1981:341) while Hymes ( 1977) tells us that language should be studied "as situated in the flux and pattern of communicative events" (1977:5).

If we accept language as a tool for social learning through community based activities then we could see concept formation and language use is closely related, in other words a child learns to think through language. In this respect Wood's (1998) analysis of children' thinking provides ample evidence of how this works in practice. One of the key areas Wood explores this idea is by looking at how children's thinking develop through collaborative and challenging activities set by teachers. I will come back to this point when I talk about practical activities in the concluding part of this paper.

Cummins (1996) talks about how the facilitation of children's cultural experiences -which he sees as embedded in the home languages- is essential prerequisite for identity building activities in the classroom. Here Cummins is not just referring to children's maintenance of their home languages supporting the development of positive identity but also the role of the home language in supporting the development of the second (target) language. In UK this means English. I will not be pursuing the bilingual debate here as it is not the focus of this paper however it is useful to remind ourselves of ample research evidence which support the view that in controlled experiments involving bilingual children and their monolingual counterparts, bilingual children outperform monolinguals in word recognition, metalingustic awareness, word invention ( Cummins, 2009).

What I would like to explore is how mainstream classroom teachers working in highly diverse environments such as London can facilitate children's identity building through utilising such linguistic and cultural experiences, I will discuss this by referring to multilingual classrooms in London and practical activities that teachers can implement to make this happen. In the final section I will be talking about a research project that highlights good practice.

All children come to school with existing language skills and a variety of experiences of talk in meaningful contexts (Vygotsky, 1978; Wells, 1985). It is important that teachers recognise and value this, and build upon the child's 'cultural capital' (Bourdieu, 1977). The child's language experiences in the home are likely to be very different from those literacy practices of the school. At home much more 
child initiated talk takes place, with language learning generally being unplanned by the adult but defined by the context within which the talk is taking place. At school teacher-led models of practice, the emphasis on 'pace' and coverage of objectives advocated in literacy strategy (DfES, 1998) has often resulted in fewer opportunities for pupil talk, (Riley \& Elmer, 2001). The preferred strategy adopted by many teachers for encouraging talk in the classroom is the Initiation, Response, Feedback (IRF) sequence (Cazden, 2001), which does not always facilitate meaningful pupil interaction.

It is also important to recognize that children who are learning an additional language do not necessarily have special educational needs (SEN). Lack of language skills in a particular language, English in this case, does not indicate cognitive challenge or learning difficulty, and lack of development in English should not be regarded as a deficit model. It is not good practice to group children with EAL (English as an Additional Language) and children with SEN together.

\section{Principles of additional language learning}

One of the key principles for additional language learning is that the learner is able to draw upon knowledge and language skills already acquired. It is very important to build upon existing skills and known experience, thus offering a reassuring context for learning. Effective language learning takes place in a meaningful context, with planned opportunities for purposeful communication (Genesee, 1987). This will involve opportunities for paired talk and group talk with peers, and adults using English and the community language where possible. Careful consideration needs to be given to the language skills required to support the task or subject matter and to how this can be incorporated into lesson planning:

Language learning in the language classroom can further the goals of content teaching by offering learners help with the language of the thinking processes and the structure or shape of content. (Mohan, 1986:1)

Language is not effectively taught or learnt in isolation. To achieve a 'language classroom' teachers will need to try to adopt an approach to teaching that integrates language and content learning, which gives pupils plenty of opportunities for meaningful contexts in which to read, talk and write. Many of these will need to start with familiar situations, which will make the additional language more accessible to 
the learner. This might involve some creative thinking about approaches to curriculum delivery, and will be increasingly possible through the cross-curricular planning approach advocated in Excellence and Enjoyment (DfES, 2003).

First language development supports the additional language acquisition. Wells (1986) has written about the importance of maintaining the whole culture and language of the home when learning an additional language. There are similarities in the processes of first and additional language learning, which can be supportive. According to Baker (2002) most bilingual children will have at least two, probably more words for objects and ideas. This means that the connections between words and concepts are looser for them, thus, allowing more fluent and creative thinking.

Having explored the theoretical framework that supports such thinking, I will now move on to talk about how this can be applied in practice. In this section of the paper I will talk about a two year research project 2007-2009) that explored how an early years centre in South London supported young children's language and identity development. I will present some of its key findings but first I am going to explore the potential of community supplementary schools (also called complementary schools) in promoting language, culture and identity formation in linguistic minority communities.

\section{Complementary schools: a historical overview}

Complementary schools go back to the mid-1800s when a sizeable Italian community was established in Clerkenwell in London, with its own church and a hospital (King, 1977a). A leading Republican intellectual, Mazzini from Rome helped establish the first Italian school and started teaching there in 1837 (Walker, 1982). In London's docklands a community school was set up to teach the children of Chinese dockers (Issa 2002).

The number of complementary schools increased from the 1950s onwards with the arrival of communities from the New Commonwealth. The first Greek Cypriot school opened in Kentish Town in London at much the same time, in response to pressures from the Greek Orthodox Church and the Greek Embassy (Tansley, 1986). The first Ukrainian mother tongue school was set up during the 1950s and well established by the 1960s (Khan, 1980). The first Turkish school was 
set up in 1959 to promote mother tongue teaching and preservation of the Turkish culture (Taylor, 1988) and other communities soon followed.

There appeared to be a pattern to setting up complementary schools: communities would follow their compatriots into urban areas where they would find employment in local economic systems. Thus the community would be increased. Soon demands from parents and community members would prompt activists and leaders in the community to seek ways of establishing a school. The schools for the Bangladeshi and Vietnamese communities during the 1970s followed a similar pattern.

The community schools were set up for more than just the maintenance of cultural, linguistic values and ethnic identity (Taylor, 1988). Several Black complementary schools were a direct response to Government policies and so-called 'compensatory initiatives' to tackle black underachievement (Plowden Report, 1967). Some complementary schools are moving away from their traditional language only policies to multiple functions to serve the needs of their communities.

A recent comprehensive study of the complementary schools (Issa and Williams, 2009) found that , although community language teaching is still provided in almost all of the complementary schools serving linguistic minorities, the focus was changing to incorporate National Curriculum (NC) subjects, giving the schools a dual purpose parents' educational aspirations for their children's achievement and the realisation of the new role of the complementary schools in facilitating such change appear to be driving this change.

The changing role of the community languages has been an ongoing debate for decades. The need for such a debate has arisen out of two main concerns on the part of the communities:

- the level of underachievement at school amongst ethnic minority communities, and

- the particular issues relating to the teaching of community languages

There appeared to be a rational justification for change, at least superficially. The real concern was related to the content of what was to be taught. Teachers often used imported resources (mainly textbooks and storybooks) featuring topics which had no relevance to the experiences of children born in the UK. Production of appropriate UK based materials 
looked like a good option but soon had to be abandoned because of the lack of time and funding. This prompted parents and community educators to consider the merits of a possible link between the community language and the English National Curriculum. Clearly this presented its own challenges. Too few of the bilingual teachers who taught in complementary schools were trained in the UK and this remains a challenge to this day. The study showed that the curriculum was taught mostly by specialist teachers of the subject (mainly maths and science) who had graduated overseas. These teachers used their initiative attending short INSET programmes to develop their knowledge of English to deliver key components of the NC subjects through their community language. This approach was found to be one of the success stories of complementary schools today. Marked increases in student numbers were recorded in schools where such provision was offered.

The study also found that the complementary schoolteachers demonstrated their high aspirations for their pupils' future by positively addressing the issue of training. In the sample of schools visited much excellent practice was found despite the challenges faced by the teachers. Although some teachers used traditional approaches, children in almost all the classes were given plenty of opportunities to develop their literacy skills in both languages. The content of teaching, especially in NC subjects, was similar to units used in mainstream schools. It was refreshing to see children expressing their satisfaction in having recognisably similar units delivered through their home languages.

Other subjects were taught too. Religious education was taught not as a separate subject but as integrated into other areas such as social studies or topic work and explored faith in the context of all religions while supporting the pupils' own cultural or linguistic development. Most schools offered extracurricular activities in the afternoon, giving children the chance to learn folk dancing, play an instrument or take part in drama activities.

\section{Language and Identity in Multicultural Settings: Ethnographic Case Studies of An Early Years Centre and Reception Classes}

The project described here (2007-2009) is headed by T. Issa and A. Hatt and is a socio-linguistic investigation of children's language use and constructions of identities. It is planned in two phases: Phase 1 in an inner city multicultural Early Years Centre and Phase 2 in its linked reception classes. The focus is to identify and 
disseminate good practice relating to language, culture, identity and awareness of others. The study is concerned with investigating how children from a variety of linguistic and cultural backgrounds are supported through a range of pedagogical practices which are based on knowledge and understanding of the emotional /social development of young children.

The Project aimed to identify and disseminate good practice relating to children's own constructions of multiple identities in multilingual and multicultural contexts. A group of children from a variety of cultural and linguistic backgrounds (including monolingual English speaking children) are chosen for the study. In the second year some of the children were followed into their mainstream reception classes to look at the degree of support they have received from the receiving schools. The findings were revealing in that nether of the receiving schools placed the same emphasis on language learning and multiculturalism. These were mostly lost at the expense of phonic and number activities. Visits to children's homes also revealed the same results when we talked to parents. Those that fully supported the activities of the nursery school appeared quite concerned about the lack of culturally oriented activities in their children's new schools.

The Project Objectives were to collect:

- Evidence of young children's understanding and interpretations of concepts such as a sense of self, similarities and differences.

- Evidence of peer-group interactions, group dynamics and adult-child interactions.

- Evidence of children's naturally occurring conversations during activities.

- Evidence of language use in different learning and social contexts.

- Examples of the kinds of practice which support the above.

- Obtain parental perceptions of how well their children were supported

\section{Some Initial Findings from available data}

Positive attitudes were observed in children towards their own languages alongside their highly developed sense of identity. In the following example Nicole is looking at the pictures of watermelon and aubergine with captions in English, Bengali and Spanish. She listens as the researcher $(\mathrm{AH})$ reads the English, Spanish and the Bengali Transliteration. 
Nicole, looking at the water melon and points to the writing: 'That says watermelon' (Nicole, age 4) (AH field notes 04/03/08)

Nicole then points at numbers on a cupboard in the technology room and says: 'Those are numbers' (AH- field notes 04/03/08), thus demonstrating an ability to differentiate between different symbolic systems

In addition to a welcoming, friendly and calm atmosphere, language awareness featured highly on the Centre's agenda. Displays featured signs and captions in different languages. The welcome sign in different languages at the Centre entrance contributed to the whole ethos of the Centre as did photos of some of the families with captions describing the use of home languages. There was also a notice-board giving information about the various Centre activities available for parents and children during each week, for example, parents and toddlers singing sessions. Children were constantly building on previous experiences relating to themselves as well as others in their environment as demonstrated in the following example:

Before the group sets off to a local ecology centre Precious (age 4) shows Alison Hatt (AH) the picture of herself and her parents in the nursery reception area. AH reads the caption to find Precious willing to acknowledge:

AH- 'We speak Yoruba at home'. Do you speak Yoruba at home?

Precious (nods). (field notes, AH- 27/03/08)

Children's awareness of different languages was also associated with countries as shown in the following example:

During observations in the outdoor play area Jedidiah (JD) (age 4) says:

$J D$ : I was born in England

AH: 'in a hospital?

JD 'No in England' (field notes, AH- 27/03/08)

In another observation, Malachi (MA) was playing on the large model wooden train:

MA: We're going to Barbados

AH: What will you do there?

MA: play with the sand and the water

$\mathrm{AH}$ : where will you stay? 
MA: In the restaurant, in the hotel...have to go on the aeroplane...train to the airport...mum and Dad lived in Barbados when I was born (AH- field notes 04/03/08)

It is useful to mention in this context that although MA is of Eritrean background his family was going to Barbados for a family wedding.

During a later observation, children were inside the 'reflection tent' (specially constructed space where children can be private or be with others looking at their images in the mirrors provided). Jedidiah (JD) bursting out looks at researchers (AH) and (TI) and says: I speak my language (Jedidiah, (AH field notes, 04/03/08)

Language awareness appears to be embedded in the ethos and everyday practice of the nursery. This was most visible in children's knowledge of their own and other languages as clearly demonstrated in the following examples:

TI: Estevon, what language do you speak?

ES: Portuguese

TI: obligado

Estevon looks at TI and smiles (TI audio recording 27/03/08)

Children's experiences were collated in individual profile books which contained pictures with captions featuring children's home as well as Centre experiences. Children were usually invited to choose and talk about the photos to be included; if children spoke a language other than English, this was presented side by side with English. Parents played a key part in this. In the following example Shaimaa is talking to Tözün (TI) about her book written in Italian, Arabic and English:

SH: here I'm playing with my baby sister

TI: (pointing at the picture of an umbrella) is that your umbrella?

SH: yes

TI: ah, you have long hair in that picture

SH: mummy cut my hair

TI: (looking at the photo) ah, I love cheesecake .

SH: yes, I like it too

TI: (Looks at Italian version) how do you say cake in Italian then? 
SH: torta

SH: (looking at her name written in Arabic) here is Shaimaa in Arabic, these are Arabic, my dad speaks Arabic

TI: Do you know Arabic?

SH: I speak Arabic, Italian and English

TI: How do you say daddy in Arabic? Is it baba?

(TI audio recording 27/03/08)

Another interesting area related to children's awareness and use of different language varieties was demonstrated in the following example by Shaimaa (the Arabic, Italian and English speaker).

In the outdoor play area, accompanied by a doll, a bag and a broom, she showed her facility with South London English variety when she said to her friend:

'Bye, darlin', I'm goin' to the mee-in' (meeting)

(Field notes AH 04/03/08)

Children's interactions with each other often reflected shared experiences through routine activities as shown in the following example where Yasemin (YS) has visited the local ecology centre 'Roots and Shoots' with a group of children. On her return to the nursery the following conversation takes place between Yasemin, Shaimaa and $\mathrm{AH}:$

$A H$ : Yasemin came to Roots and Shoots

Sh: Why?

AH: Why did we go to Roots and Shoots?

SH: Shooes?

AH: Shoots

SH: Whot?

YS: Roots and shoots Shaimaaa!!

(AH audio recording 27/03/08)

\section{Summary of initial findings from Phase 1 of the project}

During the conversations with some parents, the researchers became aware of how children's linguistic and cultural experiences from home formed the foundation for 
further development in the Centre. The initial findings of the first part of Phase 1 of the Project appear to support this. We have found that:

- Children's positive attitudes to their own languages were highly developed and contributed to their sense of identity.

- The welcoming, friendly and calm atmosphere of the Centre was clearly visible. The head teacher and the Centre staff played a key role in establishing positive links with the parents.

- Children's awareness of different languages was also associated with knowledge about different countries and places. The evidence of activities related to Knowledge and Understanding of the World (one of the areas of Learning and Experience in the current Curriculum Guidance for the Foundation Stage).

Ample examples of children's awareness were found and use of different languages. Again, this was very much supported by the Centre and reflected positively in parents' attitudes. The children's construction of multiple identities was manifested in their interactions with each other. This means that children not only had opportunities to extend their home identities but to enrich them through collaborative and shared activities in which the concept of 'the other' begins to be internalised and negotiated. The major finding of this research which has implications for teacher training is that the three thirds of the staff working at the nursery were monolingual English speaking.

\section{Summary and Conclusions}

This paper explored how children's linguistic and cultural experiences can be utilised in child centred holistic activities in multilingual/multicultural learning contexts in UK classrooms. I began by contextualising the debate and discussed the patterns of migration from countries around the world to UK and subsequent policy initiatives by successive UK governments. I discussed that with a few exceptions there was a general lack of focus and coherent language policies by the governments. I tried to link the theoretical perspectives on multilingualism and multiculturalism by talking about the findings of a two year project at a south London nursery school. The key finding of the project showed that multilingual practices were all planned and implemented by dedicated monolingual nursery staff. It is a widely accepted view that speaking another language is a useful skill to have in working in multilingual 
classrooms. To facilitate children's use of their home languages however, is a skill that can be acquired by a well trained and dedicated teacher.

\section{References}

Bakhtin, M. (1981) Discourse in the Novel in M. M. Bakhtin The dialogic imagination. Four essays by M.M. Bakhtin. Austin: University of Texas pp. $259-422$

Baker, C. (2002) Advantages of Bilingualism. Paper oresented at the TESS Conference: Gaelic Medium Secondary Education: A model for the 21st century (22 ${ }^{\text {nd }}$ March 2002), Glasgow University, Scotland.

Blauner, R. (1969) Internal Colonialism and Ghetto Revolt. Social Problems, 16, 393.

Bourdieu, P. (1977) The Outline of a Theory of Practice. Cambridge University Press, Cambridge.

Cazden, C. (2001) Classroom Discourse. Portsmouth, NH: Heinemann.

Cummins, J. (1996) Negotiating Identities: Education for Empowerment in a Diverse Society. California: Association for Bilingual Education. Cambridge: Cambridge University Press.

Cummins, J. (2009) Keynote speech, Making Multilingualism Meaningful Conference 19-20 June 2009, London Metropolitan University, UK

Department for Education and Skills (DfES) The National Literacy Strategy (1998)

http://www.literacytrust.org.uk/Policy/strat.html

Genesee, F, (1987) Learning through two languages: studies of immersion and bilingual education. New York: Newbury House

Haxell, M. A. (1979) European Immigration and Bradford. Unpublished paper. Bradford and Ilkley Community College, West Yorkshire

Hymes, D. (1977) Foundations in Sociolinguistics: An Ethnographic Approach. Tavistock, London.

Issa, T. (2002) Augmentation of Language and Thinking in bilingual Children.

Unpublished PhD Thesis, University of North London

Issa (2005) Language, Culture and identity of Turkish speaking children. Stoke on Trent: Trentham books

Issa, T. and Williams, C. (2009) Realising Potential: Complementary Schools in the UK. Stoke on Trent: Trentham, Books.

Jones, J. (1977) The Human Face of Labour. London: British Broadcasting Cocorporation.

Jones, J. (1977) The Human Face of Labour. London: British Broadcasting Cocorporation.

Khan, N. (1976) The Arts Britain Ignores: the arts of ethnic minorities in Britain. London: CRE.

Khan, V.S. (1980) The Mother Tongue of Linguistic Minorities in England, Journal of Multilingual and Multicultural Development, 1(1), 71-88.

Kozol, J. (1991) Savage Inequalities: Children in America's schools. New York: Crown Publishers.

Maybin (1994) Children's Voices: Talk, Knowledge and Identity. Clevedon: Multilingual Matters.

Mehmet A. (2001) Turkish Speaking Communities and Education: No Delight. London: Fatal Publications. 
Mohan. B. (1986) Language and Content. New York: Addison Wesley.

Riley, J. and Elmer, C. (2001) P is for Possibility. The Primary English Magazine. 7 (1), 23-25.

Ogbu, J. U. (1992), 'Understanding Cultural Diversity and Learning', Educational Researcher, 21 (8), 5-14\& 24.

Skutnabb-Kangas, T. (1984) Bilingualism or Not: The Education of Minorities. Clevedon: Multilingual Matters.

Tansley, P. (1986) Community Languages in Primary Education Report from the SCDC Mother Tongue Project. Windsor: NFER-Nelson

Taylor, M. J. (1988) Worlds Apart? Slough, NFER-Nelson.

The literacy Trust, 2006 www.literacytrust.org.uk

United Kingdom, Home Office, HOME OFFICE (1968b) Race Relations Act,

London: HMSO.

United Kingdom (1975) Language for Life: Report of the Committee of Inquiry

The Bullock Report London, HMSO.

United Kingdom (1967) Children and their Primary Schools: A Report of the Central Advisory Council for Education (England) the Plowden Report. London, Her Majesty's Stationery Office.

United Kingdom, Parliament, House of Commons (1985) Education for

All: Final Report of the Committee of Inquiry Into the Education of Children

from Ethnic Minority Groups. \{Chair: Lord SWANN\} London, HMSO.

United Kingdom, Home Office ( 2000) Race Relations Amendment Act.

Vygotsky, L. S. (1978) Mind in Society: The Development of Higher Psychological Processes, M. Cole, V. John-Steiner, S. Scribner \& E. Souberman (eds.). Cambridge: Harvard University Press.

Walker, I. (1982) Garibaldi was here, Observer [suppl] 4 April

Winder, R. (2004) Bloody Foreigners: The Story of Immigration into Britain London, Little Brown.

\footnotetext{
Author's Reference:

Dr. Tözün Issa has been a primary school teacher for 12 years and worked as an adviser for Ethnic minority Education for 6 years. After taking his doctorate at the University of North London, he became the course tutor for PGCE Community Languages course at London Metropolitan University (UK). He is currently working as group tutor for PGCE primary and Early years course and is the Director of the Centre for Multilingualism in Education. Dr. Issa is involved in a number of consultancy activities with the National Resource Centre for Supplementary Schools and CILT (National Centre for Languages) providing training for supplementary schools teachers.
} 